\title{
Quality assurance and quality control. current furtherances and hereafter point of view
}

\begin{abstract}
Quality assurance can be delineated as "section of quality management concentrated on furnishing confidence that quality must-have will be performed." The confidence delivered by quality assurance is twice intrinsically to management and extrinsically to clients, government agencies, regulators, certifiers, and third parties. An alternate delineation is "entire the aimed and organized activities accomplishment within the quality method that can be substantiated to hand over confidence that a commodity or service will perform must-have for quality. Quality assurance is across-the-board and does not have to do with the specific must-have of the product being developed. QA hobbies and responsibilities fill in practically entire of the fantabulous technique in lone fashion or distinctive, while QC is a subset of the QA hobbies. Also, constituents in the fantabulous technique might not be concretely substituted by QA/QC hobbies and responsibilities but perhaps enclose QA and QC. Quality control is a procedure which contemplates on performing the quality demand. Quality control intend to distinguish (and dead-on) imperfection in the finished product. Quality control, in consequence, is a reactive procedure. Quality control can be delineated as "section of quality management emphasized on furnishing quality must-have.
\end{abstract}

Keywords: quality management, quality assurance, quality control, good manufacturing practice
Volume 10 Issue 5 - 202I

\section{Gudisa Bereda}

Department of Pharmacy, Negelle Health Science College, Guji, Ethiopia

Correspondence: Gudisa Bereda, Department of Pharmacy, Negelle Health Science College, Guji, Ethiopia,

$\mathrm{Tel}+2519196227 \mid 7 /+251913118492$

Email gudisabareda95@gmail.com

Received: September 28, 2021 | Published: October 21, 2021
Abbreviations: GMP, good manufacturing practice; QA, quality assurance; QC, quality control

\section{Introduction}

\section{Quality management in pharmaceutical industry}

Quality management is the phase of management function that discovers and accomplishes "quality policy". Quality policy is the collectedly aim and commandment of an organization apropos of quality. Inwardly an organization, Quality assurance serves as a management tool. Manufacturers must guarantee that pharmaceutical commodities to applicable for their purposive usage, comply with the must-have of the marketing authorization and do not put patients at pitfall due to insufficient safety, quality or efficacy. To accomplish the quality existential, there must be a quality assurance system integrating GMP and Quality Control Figure $1 .{ }^{1}$ The generalization of quality assurance, GMP and quality control are interrelated phase of quality management.

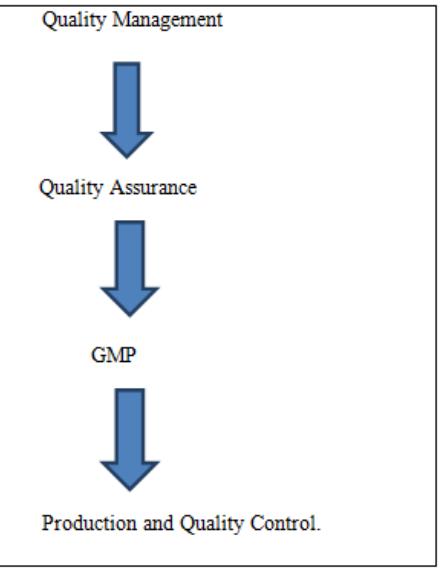

Figure I Generalization of relationships of QA, QC \& GMP in quality management.
Clients anticipate and importunity high-quality commodities. When clients acquire quality commodities the manufacturers will accelerate client devotedness, addendum redundant business, augment new clients from referrals(sending someone by the first client to the manufacturers), vindicate or ameliorate your position in the market, meliorate safety, downgrade disbenefit perils, pitch in to collectedly approbatory branding of your commodity. ${ }^{2}$ Quality is convocation the must-have, contemplation, and inescapable of the client is free from the disfigurement, dearth and monumental variants.

\section{Quality assurance}

Assurance is furnished by organization management; it signifies bestowing an appreciative asseveration on a commodity which acquires confidence for the consequence. It bestows a security that the commodity will work without any glitches as per the contemplations or inquiries. ${ }^{3}$ Quality assurance can be delineated as "section of quality management concentrated on delivering confidence that quality must-have will be performed." The confidence furnished by quality assurance is twofold intrinsically to management and extrinsically to clients, government agencies, regulators, certifiers, and third parties. An alternate delineation is "entire the aimed and methodological activities accomplishment within the quality system that can be substantiated to furnish confidence that a commodity or service will perform must-have for quality".,5 Quality Assurance is procedure based and concentrates on imperfection precluding or intends to preclude imperfection with a emphasis on the procedure used to manufacture the commodity. Quality Assurance is a proactive procedure and is forestallment in nature. ${ }^{6}$ Quality Assurance (QA) activities enclosing a aimed system of reconsideration procedures escorted by personnel not directly involutedly in the inventory compendium/development process. Reconsideration, preferably by independent third parties, should be implemented thereon a finalised inventory coming next to the implementation of QC procedures. Reappraisal confirm that data quality existential were encounter, guarantee that the inventory characterize the best feasible appraisement's of effluvium and submerge accustomed the prevailing 
state of scientific knowledge and data accessible, and advocate the effectiveness of the QC programme. ${ }^{7-11}$ Quality Assurance confirms that the approaches, techniques, methods and procedures are designed for the projects are performed correctly. ${ }^{12,13}$ Quality assurance activities observe and confirm that the procedures used to contend with and breed the compromises have been pursued and are operative. It realizes blemishes' in the procedure. ${ }^{14}$ Quality Assurance has to complete before Quality Control. It is a procedure which contemplates on furnishing assurance that quality inquiry will be finished. ${ }^{15}$ Quality assurance streamlines production and assists to assure that the final products encounter the company's quality criteria. It assures that the procedures used to design, test, and produce products will be done rightly. ${ }^{17}$ In manufacturing, quality assurance approaches, like ISO 9001, help manipulate and upgrade many procedures, enclosing: gaining raw materials, purchasing third-party constituents and subassemblies, scheming and using inspection procedures, complying with production procedures. $^{18}$ QA does not guarantee quality; preferably it begets and insures the procedures are being followed to guarantee quality. 19

\section{Quality control}

The company also put together intentions and existential for its jobholders and commodities to encounter. This guarantees that each jobholder knows what they are functioning for and what is anticipated from them. Control is to test or confirm sure-enough resultant by analogizing it with the delineated standards or where the quality manufactured commodity appertained as or delineated as "Quality of commodity as the grade in which it performs the musthave of the client. It is not outright but, it adjudicated or realized by analogizing it with some standards". ${ }^{20,21}$ Quality Control (QC) is a system of garden-variety technical activities, to gauge and constrain the quality of the inventory as it is being advanced. Quality control can be delineated as "section of quality management concentrated on performing quality must-have." So long as quality assurance interacts to how a procedure is accomplished or how a commodity is invented, quality control is further the inspection phase of quality management. An alternate delineation is "the operational strategies and activities used to perform must-have for quality." QC is a wide term, it encloses inspection at particular stage but mere inspection does not mean QC. The QC system is contemplated to: (i) furnish ordinary and concordant checks to guarantee data righteousness, correctness, and comprehensiveness; (ii) distinguish and grapple with screw-up and elision; (iii) document and archive inventory material and record entire QC activities. QC monitors activities affiliated to the examination (analytic) aspect of testing. The intention of QC is to ascertain, estimate, and counteract screw-up due to test system delinquency, environmental circumstances or operator performance, before patient resultants are reported. ${ }^{22} \mathrm{QC}$ is the section of quality management concentrated on performing quality must-have (ISO 9000:2000 [3.2.10]). Nothing more than put, it is examining "control" materials of known substances along with patient samples to monitor the exactitude and delicacy of the comprehensive analytic procedure. QC is necessitated for accreditation aspirations. Quality control is a procedure that assists a company put together implicit it bring about quality commodities and that staff and management correspondingly put together slightest imperfection. Quality control assists a company degrade excrescence and manufacture commodities efficiently those are of mega quality. QC guarantee that the approaches, techniques, methods and procedures are contemplated in the project are ensuing counteract. ${ }^{23}$ QC activities monitor and confirm that the project compromise encounter the delineated quality standards. Quality Control is a reactive procedure and is finding in nature or Quality control is product based and concentrates on shortcoming identification. It realizes the excrescency. Quality Control has to conclude after Quality Assurance. QC is a procedure which contemplates on performing the quality query. QC aims to distinguish (and rectify) imperfections in the finished commodity. QC does not control quality; preferably it measures quality. ${ }^{24}$

GMP (Good Manufacturing Practice) is section of quality assurance that guarantees commodities are concordantly manufactured and restrained to the quality standard applicable to their deliberate usage or "GMP" - is a set of principles and procedures which, when followed by manufacturers for therapeutic commonsensical, assists guarantee that the commodities manufactured will have the necessitated quality. GMPs are intended initially at depreciating the perils intrinsic in any pharmaceutical manufacturing. Such pitfalls are indispensable of two types: cross-contamination (in particular of unforeseen adulterants) and mix-ups (bafflement) caused by, instances, erroneous labels being put on containers. ${ }^{25,26}$ The three terms, QA, QC, \& GMP are continually used exchangeably, but three are genuine distinctiveness as discussed above, and particularly multitudinous people consider QA and QC are the indistinguishable and substitutable but this is not authentic. Both are firmly joined and sometimes it is arduous to distinguish the otherness. Factuality is both are affiliated to each other but they are distinguishable in origins. I.e. GMP is a constituent of quality assurance and QC is a constituent of GMP or GMP and QC are constituent $\mathrm{s}$ of quality assurance. QA and QC both are section of Quality Management notwithstanding QA is concentrating on precluding excrescence so long as QC is concentrating on distinguishing the blemish Figure 2. ${ }^{27,28}$

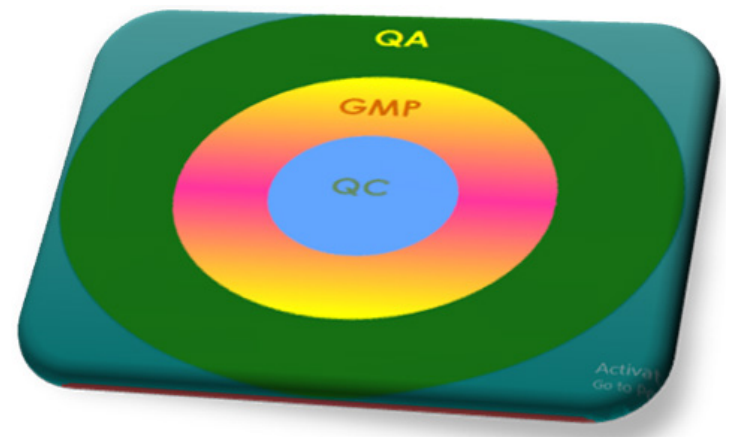

Figure 2 Relationships of QA, QC \& GMP.

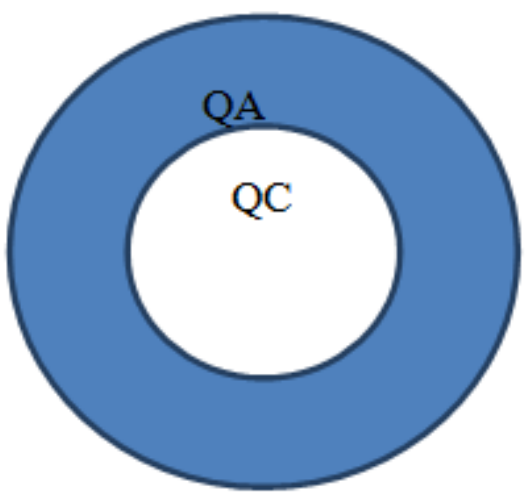

Figure 3 Relationships of QA and QC QA QC.

QA is a procedure which contemplates on furnishing assurance that quality query will be finished. QC is a procedure which contemplates on performing the quality inquiry Table 1 . 
Table I Otherness between QA and QC

\begin{tabular}{|c|c|}
\hline Quality assurance & Quality control \\
\hline $\begin{array}{l}\text { QA is the advances to generate } \\
\text { the rescue. }\end{array}$ & $\begin{array}{l}\mathrm{QC} \text { is the advances to confirm } \\
\text { that redeems. }\end{array}$ \\
\hline $\begin{array}{l}\text { QA is accountable for jammed } \\
\text { software progressive life cycle. }\end{array}$ & $\begin{array}{l}\mathrm{QC} \text { is accountable for software } \\
\text { backbreaking life cycle. }\end{array}$ \\
\hline $\begin{array}{l}\text { QA delineate standards and } \\
\text { methodologies to pursue in order } \\
\text { to bump into the client must-have. }\end{array}$ & $\begin{array}{l}\text { QC secure that the standards are } \\
\text { pursued while functioning on the } \\
\text { commodity. }\end{array}$ \\
\hline $\begin{array}{l}\text { QA behaves assure you are deed } \\
\text { the authentic things. }\end{array}$ & $\begin{array}{l}\text { QC behaves assure the resultants } \\
\text { of what you've ended are what you } \\
\text { look forward to. }\end{array}$ \\
\hline $\begin{array}{l}\text { Statistical Technique used on QA } \\
\text { is known as Statistical Process } \\
\text { Control (SPC.) }\end{array}$ & $\begin{array}{l}\text { Statistical Technique used on QC } \\
\text { is known as Statistical Quality } \\
\text { Control (SPC.) }\end{array}$ \\
\hline $\begin{array}{l}\text { QA express Planning for exploit a } \\
\text { procedure. }\end{array}$ & $\begin{array}{l}\text { QC expresses deed for performing } \\
\text { the planned procedure. }\end{array}$ \\
\hline $\begin{array}{l}\text { A QA intend is to head off the } \\
\text { excrescence. }\end{array}$ & $\begin{array}{l}\text { A QC intend is to distinguish and } \\
\text { ameliorate the excrescence }\end{array}$ \\
\hline $\begin{array}{l}\text { QA is the strategy of managing } \\
\text { quality. }\end{array}$ & $\mathrm{QC}$ is a tactics to confirm quality. \\
\hline $\begin{array}{l}\text { QA does not include performing } \\
\text { the schedule. }\end{array}$ & $\begin{array}{l}\text { QC always involves performing the } \\
\text { schedule. }\end{array}$ \\
\hline $\begin{array}{l}\text { All team constituent are } \\
\text { accountable for } \mathrm{QA} \text {. }\end{array}$ & $\begin{array}{l}\text { Exacting team is accountable for } \\
\text { QC. }\end{array}$ \\
\hline QA Exemplification: confirmation & QC Exemplification: attestation. \\
\hline
\end{tabular}

\section{Conclusion}

Quality assurance can be delineated as "section of quality management emphasized on furnishing confidence that quality must-have will be performed." The confidence furnished by quality assurance is twofold intrinsically to management and extrinsically to clients, government agencies, regulators, certifiers, and third parties. An alternate delineation is "entire the planned and systematic activities performed within the quality system that can be substantiated to furnish confidence that a commodity or service will perform must-have for quality." Quality Control (QC) is a system of ordinary technical activities, to expedient and constrains the quality of the inventory as it is being advanced. The QC system is contemplated to: (i) furnish ordinary and concordant checks to guarantee data righteousness, correctness, and comprehensiveness; (ii) distinguish and address imperfections and elisions; (iii) document and archive inventory material and record entire QC activities. QA hobbies and responsibilities fill in practically entire of the fantabulous technique in lone fashion or distinctive, while QC is a subset of the QA hobbies. Also, constituents in the fantabulous technique might not be concretely substituted by QA/QC hobbies and responsibilities but perhaps enclose QA and QC.

Data Sources: Sources searched include Google Scholar, Research Gate, PubMed, NCBI, NDSS, PMID, PMCID, and Cochrane database. Search terms included: quality management, quality assurance, quality control, and good manufacturing practice.

\section{Acknowledgments}

The authors acknowledged Endnote-8, Google scholar, Medscape, Wikipedia, and PubMed.

\section{Funding}

None.

\section{References}

1. Handbook for national quality policy and strategy: a practical approach for developing policy and strategy to improve quality of care. Geneva: World Health Organization; 2018.

2. Tarantino L, Laird K, Ottosson A, et al. Institutional Roles and Relationships Governing the Quality of Health Care: Country Experiences, Challenges, and Lessons Learned. Bethesda, MD: Health Finance \& Governance Project, Abt Associates and USAID Applying Science to Strengthen and Improve Systems Project, URC.2016.

3. World Health Organization, Organisation for Economic Co-operation, Development, World Bank. Delivering quality health services: A global imperative for universal health coverage. Geneva; 2018.

4. Primary Health Care Performance Initiative. Primary Health Care Progression Model Assessment Tool. April 2019.

5. Quality Management Program Guide. Ministry of Health and Child Care, Zimbabwe; 2015.

6. Quality Assurance Strategic Plan for Ghana Health Service 2007-2011. Ministry of Health, Ghana. 2016.

7. Strategizing national health in the $21^{\text {st }}$ century: a handbook. World Health Organization; 2016.

8. Primary health care systems (PRIMASYS): case study from Ethiopia. Geneva: World Health Organization; 2017.

9. Admasu KB. Designing a Resilient National Health System in Ethiopia: The Role of Leadership. Health Systems \& Reform. 2016;2:3:182-186.

10. Ethiopian National Health Care Quality Strategy 2016 - 2020. Transforming the Quality of Health Care in Ethiopia.

11. The Federal Democratic Republic of Ethiopia Ministry of Health. HSTP: Health Sector Transformation Plan for 2015/16 through 2019/20. 2015.

12. Ozano K, Simkhada P, Porcellato L, et al. Discussions around Primary Health Care and the Private Sector during the Global Symposia on Health Systems Research 2018. January 2019.

13. AKHS Kenya Community Health Department: Policy Brief No.4 Best Practices in Community-Based Health Initiatives Health Facility Committees: The Governance Issue.

14. Kenya Quality Model for Health Quality: Standards for Community Health Services. 2015.

15. Otiso L, Taegtmeyer M, Doyle V, et al. How can we achieve Universal Health Coverage with quality? A quality improvement model for community health from Kenya. USAID SQALE Program Policy Brief, September 2018.

16. Accelerating attainment of Health Goals: The Kenya Health Sector Strategic and Investment Plan - KHSSP July 2012 - June 2017.

17. Hazilah AMN. Practice follows structure: QM in Malaysian public hospitals. Measuring Business Excellence. 2009;:1:23-33.

18. Ministry of Health Malaysia, Country Health Plan 2011-2015. $10^{\text {th }}$ Malaysia Plan.

19. Necocheaa E, Tripathib V, Kima YM, et al. Implementation of the Standards-Based Management and Recognition approach to quality improvement in maternal, newborn, and child health programs in lowresource countries. International Journal of Gynecology and Obstetrics. 2015;130:S17-S24.

20. Ibrahim F, Dosoo D, Kronmann K, et al. Good clinical laboratory practices improved proficiency testing performance at clinical trials centers in Ghana and Burkina Faso. PLOS One. 2012;7(6):1-7.

21. Njoroge S, Nichols J. Risk management in the clinical laboratory. Annals of Laboratory Medicine. 2014;34(4):274-278. 
22. Environmental Protection Agency. EPA Basic QA/QC Concepts. The volunteer monitors guide to quality assurance project plans. Chapter3. 2014.

23. Cembrowski G. The use of patient data for process control: Its time has arrived. Clin Chem. 2000;46:S18-19.

24. College of American Pathologists. Guide to CAP Proficiency Testing/ External Quality Assurance for International Participants. 2014

25. Khatri R, Shrestha P, Sinha JN. Implementing self-sustained quality control procedures in a clinical laboratory. Journal of Nepal Medical Association. 2013;52(189):233-237.
26. Badrick T. Quality leadership and quality control. Clin Biochem Rev. 2003:24; 81-93.

27. Miller G, Erek A, Cunningham TD, et al. Commutability Limitations Influence Quality Control Results with Different Reagent Lots. Clinical Chemistry. 2011;57(1):76-83.

28. Chen M. MedlinePlus; Troponin test. National library of medicine National institutes of health. htm. 2014. 